\title{
PREMISSAS PARA O ESTUDO DA MEMÓRIA COLETIVA NO MUNDO URBANO CONTEMPORÂNEO SOB A ÓTICA DOS ITINERÁRIQS DE GRUPOS URBANOS E SUAS FORMAS DE SOCIABILIDADE.
}

\author{
Ana Luiza Carvalho da Rocha e Cornelia Eckert
}

Introdução

A descoberta das formas de vida social no meio urbano, como objeto de estudos, obrigou o antropólogo a voltar-se para sua própria sociedade na busca do entendimento de seus próprios sistemas de significações, através de uma preocupação singular com o conteúdo simbólico das cidades "enquanto representação do universo pelo homem e mediação na integração do homem nesse universo". ${ }^{3}$

Neste percurso de conformação do campo conceitual da própria disciplina, é notório o quanto a Antropologia do mundo contemporâneo deve aos intelectuais da Escola de Chicago, os primeiros a interessar-se pelo problema da desorganização, desestruturação e anomia acarretadas pela concentração das massas nas megalópoles contemporâneas. A esta vertente de estudos e pesquisas sobre a cidade, responderam outros intelectuais formados nos quadros de uma sociologia européia e dedicados ao estudo do mundo urbano e dos problemas das relações capital/trabalho, lazer, individualismo, etc.

Parte do legado de que usufruímos sobre os estudos das modernas sociedades industriais deve-se à obra de Georg Simmel e sua atração intelectual pela diversidade indefinida das formas de vida social no mundo contemporâneo. Em suas análises sobre a vida metropolitana e a filosofia do dinheiro, Simmel revelou-se, para o campo de estudos da Antropologia das sociedades contemporâneas, um pensador eternamente fascinado tanto pela riqueza das formas de vida social e sua capacidade de acolher uma infinidade de conteúdos quanto pela riqueza de tais conteúdos que podem, da mesma maneira, acolher uma multiplicidade de formas.

A vida metropolitana, apreendida no contexto do pensamento simmeliano, revela-se como ponto de interseção de vários mundos, isto é, "uma continuidade não-regularizada de

\footnotetext{
${ }^{1}$ Revista Margem Tecnologia, Cultura. Faculdade de Ciências Sociais - PUC - SP, EDUC- FAPESP. Numero 8. 1998. P. 243 à 259. Margem@uol.com.br

${ }^{2}$. Agradecemos ao CNPq pelo concessão de bolsa produtividade no projeto integrado "Estudo antropológico de itinerários urbanos, memória coletiva e formas de sociabilidade no mundo urbano contemporâneo", à Fapergs pelo financiamento do Projeto Banco de Imagem.
} 
formações, informações e deformações de conteúdos novos e antigos que se individualizam nas formas que os animam, de tal modo que no desenvolvimento vital aquilo o que é cada vez formado ultrapassa a forma momentaneamente adotada". Formas estas dadas pela diversidade de combinações das afiliações dos indivíduos aos grupos, em que as interações estão sujeitas ao espírito da vida moderna.

\section{Contornos do pensiero debole ${ }^{5}$ nos estudos sobre as culturas contemporâneas}

Sob o invólucro das "Sociedades Complexas", mais recentemente, as formas de vida social no meio urbano tornam-se objeto de indagação aos olhos dos antropólogos sob o comentário atento de Georg Simmel: "A vida engloba em um só ato a limitação e o deslocamento do limite". ${ }^{6}$ A ênfase analítica dá-se sobre as formas de organização e interação entre indivíduos e suas redes de relações como campos de negociação da realidade em múltiplos planos. Marcadas por processos dinâmicos de transformações, investigam-se os sistemas de representações mentais (imagens e valores) que caracterizam a vida na cidade ${ }^{7}$, as "regiões morais" e suas "províncias de significado" "8 que se colocam a partir do revelado emicamente e traduzidos num discurso antropológico sobre o "outro"; lá onde a própria idéia de "negociação da realidade" implica não só o reconhecimento da diferença como elemento constitutivo da sociedade ${ }^{9}$ mas a arbitrariedade da escritura etnográfica. ${ }^{10}$

A Cidade assume, assim, um lugar estratégico como locus privilegiado para a reflexão antropológica em sua busca de apreender, a partir de uma perspectiva compreensiva, tanto a "comunicação" que preside as formas de vida social no meio urbano, como as multiplicidades e as singularidades que encerram o vivido humano no interior deste espaço existencial criado pelo homem da civilização. Nas grandes metrópoles, a vida humana torna-se objeto principal de estudo pelos "retalhos, os resíduos", "secundário ou excêntrico": a moda, o jogo, o colecionador, os dioramas, a prostituição, o flâneur, as passagens, o interior, as ruas, a fotografia, o réclame". ${ }^{11}$

\footnotetext{
${ }^{3}$. LEROI-GOURHAN, A. O gesto e a palavra, técnica e linguagens. Lisboa, Edições 70, 1965.

${ }^{4}$ FREUND, J. "De Max Weber à Georg Simmel”, In: SOCIÉTÉS, Revue des Sciences Humaines et Sociales, Paris, Dunod, $1992, n^{\circ} 37$, p.219.

${ }^{5}$ Cf. expressão cunhada por VATTIMO, G. La fin de la modernité, Paris, Seuil, 1987., em sua análise da "cultura pósmoderna".

${ }^{6}$ SIMMEL, G. apud LÉGER, F, La pensée de Georg Simmel, Paris, Kimé, 1989, p. 289.

7. SIMMEL, J. Sociologia. Estudios sobre las formas de socializacion. Buenos Aires, Espasa-Calpe, 1984, p. 61.

${ }^{8}$ SCHUTZ, A. Estudios sobre teoria social. Buenos Aires, Amorrortu editores, 1972.

9. VELHO, G. Projeto e metamorfose. Antropologia das sociedades complexas. Rio de Janeiro, Zahar, 1994, p. 21-22.

${ }^{10}$. CLIFFORD, J. y MARCUS, G. E. (Eds). Retoricas de la Antropologia. Madrid, Serie Antropologia, Jucar Universidad, 1991.

${ }^{11}$. CANEVACCI, M. A cidade polifônica. Ensaio sobre a antropologia da comunicação urbana. São Paulo, Studio Novel, 1993, p. 107.
} 
Em nome da sua perspectiva materialisticamente teológica, Benjamin nos ensina que na Cidade o objeto da redenção não é unicamente o presente-futuro mas também o passado. Com Benjamin, a narrativa urbana não se utiliza de nenhum recurso estilístico "precioso" para se configurar: "Somente farrapos e refugos, não para fazer o seu inventário, mas sim para fazer-lhes justiça da única maneira possível: usando-os". ${ }^{12}$

Eis por que se torna aqui interessante pontuar o lugar estratégico que hoje ocupa o estudo dos itinerários dos grupos urbanos e de suas formas de sociabilidade na compreensão do mundo urbano contemporâneo. O deslocamento dos grupos/indivíduos entre as "províncias" e "territórios" de significação nas cidades é uma das questões cruciais para se compreender o fenômeno da memória coletiva e, por conseqüência, da estética urbana das modernas sociedades urbano-industriais.

É através do estudo dos itinerários urbanos e das formas de sociabilidade, das intrigas e dos dramas que configuram o teatro da vida citadina, apreendidos como uma espécie de mapeamento simbólico do movimento da vida que se pode, nos dias de hoje, refletir sobre a complexidade sociológica das estruturas espaço-temporais sob as quais se assentam os fenômenos da alteridade e da experiência humana no mundo contemporâneo.

Reconhecendo-se que o fenômeno urbano é o resultado da ação recíproca de indivíduos e de grupos no plano de trocas sociais, cabe destacar aqui a importância do estudo das formas específicas dos arranjos da vida social que aí se processam, segundo a complexidade dos gestos acumulados de seus habitantes, seja para a compreensão do processo de territorialização/desterritorialização de identidades sociais no mundo contemporâneo; seja para o entendimento da descontinuidade/continuidade sistêmica de valores acionados, de redes/espaços sociais que situacionam os sujeitos segundo suas trajetórias, posições e papéis, suas adesões e suas dissidências no contexto citadino.

Sobretudo, visto sob o ângulo da transformação mundial das culturas, é a produção da Diferença em termos dos processos microscópicos, no que concerne à adequação/transformação entre forma social e fluxo vital, instituições e comportamentos individuais e coletivos, que pode elucidar sobre o "como" e o "porquê" dos laços coletivos e os contextos sociais onde são vividos e negociados.

No plano das ciências humanas, a produção da Diferença ${ }^{13}$ atinge outras proporções: qual o lugar que ocupa a desordem ${ }^{14}$ na formulação do pensamento antropológico por vezes

\footnotetext{
12. CANEVACCI. Idem. p. 107.

${ }^{13}$ Referimo-nos aqui menos à obra de DELEUZE, G. Différence et répétition, Paris, PUF, Seuil, 1968, que a obra de VATTIMO, G. Les aventures de la différence, Paris, Editions Minuit, 1985, onde o autor, reverenciando o pensamento de W. BENJAMIN, precisamente sobre a experiência do homem das grandes metrópoles, analisa o declínio do sujeito da
} 
asfixiado pela obsessão de encontrar "leis" absolutamente necessárias e universais para vida social. A destruição/reconstrução de singularidades culturais e regularidades locais, cada vez mais remete, o antropólogo a pensar as referências de tempos vividos e ordenados na experiência ordinária dos atores sociais como forma de atribuir significação aos seus atos/pensamentos. $^{15}$

O mundo urbano contemporâneo, desafios a uma interpretação das formas

\section{informes}

Em Antropologia, o campo fértil para o conhecimento deste processo tem sido a análise da dinâmica da vida urbana, pois a Cidade é um território expressivo da experiência temporal contemporânea dos grupos humanos que nela habitam, não sendo suas estruturas espaciais e as formas de vida social que aí se processam um aspecto banal e evidente de suas vidas cotidianas.

A compreensão do fenômeno de construção/destruição das cidades tanto quanto o entendimento do ritmo da decomposição das experiências sociais dos grupos urbanos em seus territórios podem significar importantes formas de se rastrear a inteligibilidade do fenômeno do vivido humano contemporâneo na era da técnica, longe da idéia de uma "cidade superexposta". 16

Se o contexto urbano se projeta, aqui, nas formas de comunicação que nele são produzidas, a partir de uma "tradição", "vista não mais como aquele conjunto complexo unitário, mas sim como uma polifonia de subjetividades diversas", ${ }^{17}$ a cidade que parecia antes homogeneizar corpos se desvenda, entretanto, nos dias de hoje, sob o enfoque dos estudos do cotidiano como espaço onde coexistem, por excelência, diferentes estilos de vida,

tradição metafísica (burguês-cristão) e seus reflexos no estudo do mundo contemporâneo (do "despertar do ser") e onde o sujeito não se deixa mais perceber como presença, estabilidade, fundamento absoluto, mas como "finitude", "ser-para-a morte".

${ }^{14}$ Os comentários de BOUDON, R. La place du désordre, critique des théories du changement social. Paris, PUF, 1984, permanecem, ainda hoje, bastante pertinentes.

${ }^{15}$ Não por acaso, é interessante aqui citar as obras de DE CERTEAU como estratégias aos olhos dos antropólogos preocupados com o estudo do mundo urbano contemporâneo. A referência a este autor tem sido freqüente para o caso do reconhecimento, por parte dos antropólogos, de que o processo de fabricação de teorias contemporâneas deve retornar à realidade das práticas cotidianas dos grupos/indivíduos e a seus "saberes não-sabidos" como forma de recolocar o tema da "multidão sem qualidades" sob outro prisma: "o das artes do fazer". DE CERTEAU, M. A invenção do cotidiano: artes de fazer. Petrópolis, Vozes, 1994; DE CERTEAU, M. A Cultura no Plural. Campinas, SP: Papirus, 1995.

${ }_{16}$ Pensar aqui alguns autores que tratam do tema da arquitetura e das políticas urbanas para delas retirarem reflexões catastróficas sobre a era tecnológica que preside a lógica das sociedades ditas "pós-modernas" e o fenômeno do desencaixe espaço/tempo e seus efeitos sobre as formas de vida social no mundo contemporâneo; por exemplo, VIRILIO, P. O espaço crítico, RJ, Editora 34, 1993.

17. CANEVACCI, M. A cidade polifônica. Ensaio sobre a antropologia da comunicação urbana. São Paulo, Studio Novel, 1993, p. 63. 
visões de mundo e ethos chamados constantemente a resistir ao tempo do desgaste e do desaparecimento de seus referentes materiais. ${ }^{18}$

Sob os cânones do niilismo da cultura pós-moderna e dos postulados do individualismo moderno em fase de desesperança, muitas vezes repertoria-se o mundo urbano contemporâneo a partir das formas, mais ou menos intensas, de desarticulação entre lugares e pessoas, entre espaços e afetividades que se degradam, revelando trajetórias, enraizamentos ou rupturas que correspondem, por vezes, a uma estetização da violência, etc. ${ }^{19}$

Eis aí a importância de se empreender um giro interpretativo. Trata-se de se re-pensar as próprias categorias de entendimento com as quais invocamos o fenômeno do mundo urbano contemporâneo e o fundo comum de sentido a que pertencem.

Primeiro giro, afastar-se do moralismo de um pensamento dogmático que concebe a Cidade a partir de princípios de ordem, para se aproximar de uma abordagem das formas de vida social nas modernas sociedades urbano-industriais sob a ótica das formas sensíveis do vivido humano. Ou seja, do stock de "províncias de significados" de que os indivíduos dispõem para se identificarem a um tempo vivido, referenciado a um espaço em constante mutação (não apenas por seus limites geográficos, mas por sentimentos de pertencimento, por referenciais de reconhecimento, de produção, de troca, de trabalho, de lazer). ${ }^{20}$

O segundo giro, atingir um patamar de aceitação sobre a realidade de uma concepção de mundo social, pela ótica do vivido e do cotidiano, e aproximar de um enfoque compreensivo do mundo urbano contemporâneo que se apóie sobre o caos, a não-linearidade, a desordem, a turbulência e as catástrofes como via de acesso à compreensão da sociedade humana, contemporânea ou não. ${ }^{21}$

\footnotetext{
${ }^{18}$ Estamos longe de contrapor, aqui, as ordens sociais tradicionais aos temas das instituições sociais modernas, nos termos muitas vezes colocados por autores preocupados seja com as "descontinuidades da Modernidade, seja com a nova ordem pósmoderna. Sob a ótica dos estudos de memória coletiva, o que se quer pontuar aqui é o fato de não ser excludente, se pensar a "civilização urbana", "moderna", "tecnocrática" e iconoclasta nascida na Europa Ocidental, e suas filosofias da consciência e da história, e se refletir sobre seu compromisso com a escolástica aristotélica e cristã, ou seja ,a tradição a que pertence nos termos de uma transposição terrestre de um tipo de civitas Dei, cf. GANDILLAC, M. Gênese da Modernidade, RJ, Ed. 34, 1995.

${ }^{19}$ Ver a respeito toda uma literatura considerada "neo-individualista" que tende a ver, sob a ótica do pessimismo, as transformações recentes pelas quais passam as modernas sociedades urbano-industriais. SENNET, R. O declínio do homem público. São Paulo, Cia das Letras, 1988; LASCH, C. A cultura do narcisismo. Rio de Janeiro, Imago, 1983; BERMAN, M. Tudo que é sólido desmancha no ar. A aventura da modernidade. São Paulo, Companhia das Letras, 1986; e LIPOVETSKY, G. L'ère du vide, essais sur l'individualisme contemporain. Paris, Gallimard, 1993, etc.

${ }^{20}$ Nos termos de LUHMANN, N. "La complexité et le sens", In: Science et pratique de la complexité. Montpellier, Idate, 1984, apud WATIER, P. “À propos des quelques thémes de la sociologie de N. Luhmann”, In: SOCIÉTÉ, Revue des Sciences Humaines et Sociales, Paris, Dunond, 1994, n 43; trata-se de restituir ao fenômeno das culturas contemporâneas, um espaço à múltiplas dimensões, considerando-se que a sociedade humana (enquanto forma-sistema) se configura através de uma multitude de sentidos que se atualizam simultaneamente.

${ }^{21}$ Embora não seja objeto deste artigo, é importante mencionar as aproximações necessárias, nos estudos das culturas contemporâneas, entre a "sociologia das formas" de Simmel e as teorias do Caos e das Catástrofes que poderiam nos ajudar a elucidar a aparente turbulência, "provisória" ou "efêmera" dos fenômenos culturais no mundo contemporâneo e suas flutuações em torno de "pontos regulares" e "pontos de revolução", quando vistos sob a ótica de uma análise microscópica da vida social e de seus sistemas de pertencimentos. Cf. DORFLES, G. Elogio à Desarmonia. São Paulo, Martins Fontes, 1986.
} 
Terceiro giro interpretativo: recolocar, pela via dos estudos antropológicos sobre o mundo urbano contemporâneo, a Cidade, enquanto objeto temporal, sob a perspectiva de uma sociologia figurativa de seus espaços, matéria das ações de grupos/indivíduos e território de projeção e de enraizamentos de suas motivações simbólicas. A paisagem do mundo urbano contemporâneo guarda, neste contexto, as feições das estratégias de vida de seus habitantes, seus sonhos e desejos, segundo a acumulação benéfica da animação e da vibração temporal dos ritmos diferenciais de ocupação/apropriação de seus territórios. ${ }^{22}$

Quarto giro interpretativo, considerar a Cidade sob o plano de sua fenomenologia existencial. Isto é, restituir-lhe o estatuto de espaço vital, território multidimensional da espécie Sapiens, configurado de "ambiências emocionais" que antecedem a sua mera geometria espacial. Numa démarche objetal, a Cidade se mostra aos olhos dos antropólogos a partir dos gestos, olhares e performances de seus moradores; dos itinerários, dramas e intrigas vividos por eles; das formas de sociabilidades e das linguagens ordinárias da rua, todos descritores desta "topofilia" que re-envia as projeções individuais e coletivas dos traços de uma cultura e de uma civilização. A Cidade ressurge enquanto manifestações expressivas dos gestos humanos que lhe fazem ascender a status legítimo de "espaço habitado", graças a sua autonomia absoluta como espaço poético, repleto das histórias e das imagens a ela atribuídas. $^{23}$

Em decorrência, os espaços urbanos construídos e vividos, como objeto etnográfico, vão se revelando não meros reflexos de políticas urbanísticas mas suportes de tradições e biografias de seus habitantes cujas narrativas expressam uma linguagem coletiva que comunica uma pluralidade de identidades e memórias, remetendo seus territórios aos pretextos e às manipulações humanas.

Neste sentido, os espaços públicos e/ou outros do domínio privado fornecem o suporte material de um investimento simbólico referido ao cotidiano afetivamente significativo de seus grupos sociais. Não se pode esquecer aqui que toda obra humana remete a uma produção simbólica, sendo os territórios de sociabilidade de uma cidade nichos de sentidos produzidos por uma comunidade, não para concluir aí apenas sobre os sistemas de dominação

\footnotetext{
${ }^{22}$ Cf., nesse caso, autores como SANSOT, P. Les formes sensibles de la vie sociale, Paris, PUF, 1986 e SANSOT, P. Poetique de la ville. Paris, Méridiens Kliencksieck, 1998;

A. MOLES e E. ROHMER, 1982. MOLES, A e ROHMER, E. Labyrinthes du vécu, Paris, Méridiens, 1982.

${ }^{23}$ Considerando estudos sobre estética urbana e as feições da crise e do medo nas sociedades contemporâneas, inspiramo-nos aqui em algumas reflexões em torno de autores como COX, H. A cidade do homem, RJ, Paz e Terra, 1971 e HILLMAN, J. Cidade \& Alma. SP, Studio Nobel, 1993, que propõe a cultura e a idéia de caos, catástrofe e desordem crônica no mundo contemporâneo sob a ótica da anima mundi, ou seja, "as formas animadas oferecidas a cada evento como ele é, sua disponibilidade para a imaginação, sua presença como realidade psíquica”.
} 
subjacentes, mas para interpretar sobre os significados que configuram as diferentes formas e planos de existência social em seu interior.

Assim, indiferente ao desaparecimento dos referentes materiais dos espaços sobre os quais os grupos/indivíduos fundam sua identidade (mobilidade residencial, remoção de bairros antigos, transformação espacial e destruição urbana), a Cidade, em sua polissemia, torna-se o testemunho dos jogos da memória de seus "agentes", espaço fantástico onde eles podem "colar" sua existência a certos momentos de interação social vividos em seus territórios e investi-los do próprio ritmo construído no corpo da duração de biografias de vida.

\section{Itinerários urbanos e narrativas, a cidade como objeto temporal}

É nos itinerários urbanos e nas narrativas que produzem os habitantes das grandes cidades contemporâneas sobre seu vivido urbano que se coloca o desafio de se restituir a legibilidade dos fenômenos da cultura nas sociedades contemporâneas, conferindo-lhes, a um só tempo, um senso à existência da vida comunitária em seu interior e uma reatualização da monumentalidade de seus tempos plurais, posto que "não existe nenhuma razão, natural ou não, para que uma sociedade se conserve, salvo justamente a sua cultura, que é o instrumento de luta contra a dissolução no Tempo". ${ }^{24}$

$\mathrm{Na}$ Europa Ocidental, a Cidade, pela tradicionalidade das utopias que encerra, compõe-se de um sistema de signos culturais tensionais uma vez que a designação de sua função "eucarística", tanto quanto a representação de sua "aura" e a consagração de seu poder simbólico contrapõem-se inúmeras vezes aos discursos que seus habitantes tecem sobre ela.

Tomar a Cidade como objeto temporal significa, aqui, contemplar o acontecimento urbano a partir seja da imagem mnésica que este sugere aos atores sociais, seja do fundo comum de sentido ao qual pertence. Espelhando referenciais culturais de um passado coletivo, a vida urbana recompõe-se num tempo coletivo. Trata-se de reconhecê-la, através das narrativas e dos itinerários de indivíduos/grupos neste jogo de eterna reinvenção de "práticas de interação" de seus habitantes. ${ }^{25}$

Nas modulações das formas de vida coletiva, encadeadas por ritmos que se conciliam e se sobrepõem no meio urbano, concebe-se o tempo e o movimento nos efeitos de configuração no sentido de Norbert Elias, ${ }^{26}$ ou seja, na análise das formas múltiplas de interdependências sociais. Pelas configurações dos relatos de seus habitantes e dos processos

\footnotetext{
${ }^{24}$. DUVIGNAUD, J. La solidarité. Liens de sang et liens de raison. Paris, Fayard, 1986.

25. GOFFMAN, E. Les rites d'interaction. Paris, De Minuit, 1974, p. 42.

26 . ELIAS, N. Introdução à Sociologia. Lisboa, Edições 70, 1980.
} 
interativos, pelas imagens e práticas dos indivíduos, pode-se redimensionar a Cidade como objeto que realiza um obra temporal na medida em que seus territórios e lugares se prestam ao enraizamento de uma experiência comunitária de constante reordenação de um viver coletivo.

Para Norbert Elias aqui haveria um encadeamento de situações históricas e de experiências comuns que refletem um vivido em nível da nação, da civilização, definidas como quadro social da memória coletiva ocidental, onde "o observador, simultaneamente, observa a prática e situa sua própria maneira de ver a un palier do processo. A consciência de si (do antropólogo) deveria sem dúvida também ser apreendida na sua gênese. A memória coletiva dos indivíduos ocidentais é também a sua". ${ }^{27}$

Assim, pode-se redimensionar a Cidade como objeto que realiza uma obra temporal uma vez que seus territórios e lugares se prestam ao enraizamento de uma experiência comunitária de constante reordenação de um viver coletivo.

O "passado" urbano, então, não é necessariamente antagônico ao "presente" posto que, conforme Bachelard, "nosso passado inteiro também vela atrás de nosso presente". ${ }^{28}$ Assim, para se compreender o processo dinâmico de mutação e turbulências das formas de vida na cidades do mundo contemporâneo, torna-se necessário levar-se em conta o tempo presente do vivido de seus habitantes narrado por eles próprios. O "tempo social", neste caso, é o produto de um processo de consolidação temporal pensado por uma comunidade, fruto da hierarquização de uma série de instantes e de rupturas de trajetórias vividas. Evita-se perceber a história de uma cidade exteriormente às modalidades simbólicas de controle do tempo expressas pelos grupos/indivíduos e agenciadas no contexto de seus ambientes psicohistóricos. ${ }^{29}$

Daí a importância de se investigar a Cidade como objeto temporal a partir da forma como os sujeitos pensam a ordenação de superposições temporais vividas, "tempos recusados e tempos utilizados", "tempos ineficazes e tempos coerentes, organizados e consolidados numa duração". ${ }^{30}$ Pela dinamização da memória de uma comunidade urbana, seus agentes consolidam uma temporalidade vivida como coletiva, rica em significações. Através dos "jogos da memória" que revelam suas narrativas, ultrapassa-se o enfoque do meio urbano

\footnotetext{
27 . BOURDARIAS, F. "Norbert Elias: les techniques du regard”. In. Sociétés. Revue des Sciences Humaines et Sociales. Paris, Dunod, $\mathrm{n}^{\circ} 33,1991$. p. 259.

${ }^{28}$. BACHELARD, G. A dialética da duração. São Paulo, Ática, 1988, p. 11.

${ }^{29}$ Adotamos para a análise da Cidade como objeto temporal as reflexões de DURAND, G. Les strucutres anthropologiques de l'Imaginaire. Paris, Dunod, 1984, ao situar a produção do fenômeno urbano como parte do trajeto antropológico do homem, ou seja, o fruto das acomodações das pulsões subjetivas humanas às intimações do seu meio cósmico e social. $\mathrm{O}$ espaço urbano aparece, assim, como parte da expressão de uma "fantástica transcendental", onde se situa o fenômeno da memória, ao permitir aos seus habitantes "remontar o Tempo" e perenizar suas ações no mundo.

${ }^{30}$. BACHELARD, G. A dialética da duração. São Paulo, Ática, 1988, Capítulo 5.
} 
como "caos", "ruína" e desordem, pois nele o cotidiano da Cidade é reinventado e se encontra carregado de sentido.

No Brasil, viver a cidade tem se revelado um ato de arrumar, encadear e encaixar as diversas estruturas temporais e espaciais dos ritmos das trajetórias e histórias de grupos humanos que nela habitaram, num esforço de estabelecer um tempo humanitário que se solidarize com a tarefa de seus habitantes de construir uma durée. ${ }^{31}$

Ritmos e ressonâncias, entonações fortes ou fracas, estilos melódicos ou dramáticos, tonalidades harmônicas ou dissonantes, cadências dinâmicas ou lentas, movimentos de encantamento ou de desencantamento, mas jamais ausência de ritmo, ${ }^{32}$ este é o estilo do "viver a cidade" sob os Trópicos. ${ }^{33}$

\section{Cotidiano, memória coletiva e a Cidade, ou a matéria opondo-se à vida}

A Sociologia e a Antropologia brasileira se caracterizam por investir na descoberta de novos e eficazes instrumentais teórico-metodológicos para compreender os fenômenos de uma progressiva urbanização de suas cidades, as mudanças na estrutura produtiva associadas à industrialização e todos os processos decorrentes dos diferenciados padrões de urbanização, de concentração da renda, problemas gerados pelo modelo econômico e manifestos nas desigualdades sociais.

Freqüentemente, nas abordagens de tais campos disciplinares, os indivíduos e grupos sociais aparecem experienciando a vida urbana de formas diferenciadas, hierárquica e economicamente distintos, sendo que poucos são os portadores de capital, e a maioria fornecedora da força de trabalho.

A população urbana no Brasil ocupa desigualmente os espaços em cidades industriais reguladas por ritmos de crescimento desordenados, sobre as quais se debruçam planos diretores e políticas públicas urbanas embriagadas do ideal progressista e de modernização, indiferentes e distanciados da própria tradição da trama da vida urbana à qual pertencem as cidades latino-americanas.

\footnotetext{
${ }^{31}$ Importante aqui situar a trilogia da obra de G. FREIRE (Casa-Grande e Senzala, Sobrados e Mocambos e Ordem e Progresso) como desafio para se pensar o ritmo das acomodações do tempo através das quais a civilização urbana no Brasil se implantou, diferenciando-se nitidamente desde uma perspectiva da cidade colonial, cidade imperial e cidade democrática, cf. ROCHA, A. L. C da. "Le sanctuaire du désordre, l'art de savoir-vivre des tendres barbars sous les Tristes Tropiques". Tese de doutoramento, Paris V Sorbonne, 1994.

32. Cf. ECKERT, C. "Memória e Identidade. Ritmos e ressonâncias da duração de uma comunidade de trabalho: mineiros do carvão (La Grand-Combe, França): In: Cadernos de Antropologia n 11, Porto Alegre, Ed. UFRGS, 1993.

${ }^{33}$ Cf. ROCHA, A. L.. C da. "A irracionalidade do belo e a estética urbana no Brasil", In: BRANDÃO, C.R. e MESQUITA, Z. (Orgs.). Territórios do Cotidiano, uma introdução a novos olhares e experiências, POA/Sta Cruz, Ed. UFRGS e EDUNISC, 1995
} 
O ritmo da dinâmica e da expansão urbana das grandes metrópoles brasileiras aparece de forma alucinante e autofágica. Por um lado, a Cidade tem que responder aos processos incessantes de absorção de grupos sociais que elevam a densidade demográfica a índices alarmantes a partir de fluxos migratórios (campo/cidade), por outro, para crescer, a Cidade é destruída, demolindo-se antigas referências espaciais de seus antigos moradores. Na busca da ampliação dos equipamentos urbanos, desintegram-se redes sociais e sentimentos de pertencimento (vizinhança, bairro, etc).

Os estudos antropológicos acerca do tempo impresso na vida urbana das cidades do Brasil vislumbram um tensionamento ilimitado entre as transformações econômico-sociais e o vivido humano. Neste sentido, cada vez mais se coloca a necessidade de se enfrentar a problemática da individualização na sociedade urbana e do processo de fragmentação/universalização de realidades diversas entre seus grupos sociais.

É importante dar conta desta dinâmica da continuidade/descontinuidade de universos simbólicos que contempla os territórios da vida urbana no Brasil, em que grupos/indivíduos co-dividem, num mesmo espaço, relações extremamente diversas, muitas delas de forma mais isolada, outros se reagrupando em associações, outros ainda interagindo em redes mais ou menos informais, de qualquer maneira sempre dimensionando sistemas de valores, de imagens, de códigos, formas de pensar e exprimir-se diferencialmente.

Neste contexto aparentemente caótico e desordenado, o estudo da memória individual e coletiva é a chave para se elucidar indivíduos e grupos que geram, produzem e transmitem conjuntos de significados sobre os territórios urbanos em que habitam, mediando projetos sociais e culturais como referência de sentido para sua ação no contexto das complexidades dos processos de trocas e interações sociais.

A Cidade é, sem dúvida, um repositório de excedente de sentidos e, em seus territórios, os sujeitos vivem cotidianamente estratégias de negociação de realidades, de opções de consumo, de escolhas de interação, etc. Neste sentido, tem sido recorrente na produção teórica da Antropologia urbana do Brasil, a busca de compreensão de continuidades de sentidos vividos no passado dos grupos urbanos através do estudo da reordenação de referências de identidade que a durée social lhes permite. ${ }^{34}$

Apesar da forte predominância, nas múltiplas representações dos citadinos (opiniões, discursos, imprensa, meios de comunicação de massa) e de alguns intelectuais, de

34. Durée (duração) social no sentido dado por BACHELARD, G. A dialética da duração. São Paulo, Ática, 1988. 
representações catastrofistas do mundo urbano no corpo do pensamento social brasileiro, os "tempos de crise" não são vazios de significação.

Se valoradas positivamente pelo pensamento antropológico, as rupturas e as descontinuidades vividas por indivíduos/grupos no interior da paisagem urbana do país, em constante mutação e agitação, nos informam dos esforços dos habitantes de suas grandes metrópoles para superar tanto o destino mortal da civilização urbana à qual pertencem quanto a matéria perecível dos atributos de sua identidade social.

Nessa perspectiva, estudos e pesquisa mais detalhados sobre o fenômeno da memória coletiva e da estética urbana, numa perspectiva que alia as análises macro e microssociológicas dos fenômenos culturais na e da Cidade, aparecem não apenas como referência essencial para o entendimento da reconstrução de identidades de grupos/indivíduos na realidade contemporânea do país, do re-pensar de seus valores e estilos de vida, da reorganização de seus projetos e aspirações, mas também como instrumento para se refletir sobre o viver urbano que aí se processa.

Conscientemente ou não, através de suas práticas e representações, os habitantes, os citadinos, retomam um ritmo cotidiano outro ao se apropriar cotidianamente do territórios dos grandes centros industriais do país. Face às agitações temporais, eles re-atualizam sua vida familiar, re-configuram redes sociais diversas de pertencimento, atribuindo sentido as suas práticas urbanas.

Observar o ritmo das ações de construção de sentido que tecem os indivíduos/grupos para o seu "viver a cidade" é perceber o processo de consolidação de um tempo coletivo urbano que os ultrapassa mas que lhes confere um lugar determinado na forma como suas decisões se alocam num espaço determinado. É através da sobreposição de tempos vividos e de tempos pensados pelos habitantes das grandes cidades, reencontrados na vida do dia-a-dia, que se pode pensar o tempo social como durée (duração).

Somente considerando-se tais tempos re-pensados e espaços re-encontrados é que se pode desvendar que, no mundo urbano contemporâneo, malgré o niilismo de muitos, a vida comunitária se reconstitui, não sem um certo esquecimento (seletivo) do passado ou rupturas dolorosas que representam as experiências novas. Para se compreender a estética da vida urbana que se processa nas modernas sociedades industrias há que se atribuir aos fenômenos temporais um lugar estratégico nos estudos antropológicos do mundo contemporâneo, pois cada vez mais o desafio que o pensamento das ciências sociais sofre, é menos a compreensão dos fenômenos da cultura a partir de seus arranjos espaciais, mas sua dispersão enquanto decisões de indivíduos/grupos no tempo. 
Porque a análise temporal conduz o antropólogo a pensar a ondulação dramática dos fenômenos culturais no mundo urbano, ela lhe dá acesso a refletir sobre a unidade dos fenômenos culturais como uma adesão global de grupos/indivíduos a determinadas ações/desejos/expectativas comuns tanto quanto pensar a sua diversidade como recusa a outras, numa sucessão descontínua. Neste ponto, parafraseando Bachelard, a matéria dos fenômenos culturais no mundo contemporâneo dependeria de decisões de indivíduos/grupos mais no tempo que no espaço. ${ }^{35}$

O tempo é, portanto, contemporaneamente, uma dimensão significativa para se investigar a experiência humana nas grandes cidades industriais do mundo contemporâneo. Sem observar as feições do tempo que engendra o mundo urbano nas sociedades contemporâneas torna-se quase impossível, nos dias de hoje, desvendar o significado da apropriação e reelaboração das referências culturais e sociabilidades que fazem com que a vida coletiva nas grandes metrópoles dure no tempo no sentido do arranjo de suas descontinuidades.

Longe do tratamento "museal" das identidades culturais no meio urbano, o que é fundamental é investigar como se processam as ordens de figuração da inovação, da evolução e da mutação de tradições culturais no meio urbano que expressam sempre uma invariância a ser constantemente re-lembrada e re-atualizada, mesmo que se refiram a passados reais ou irreais que compõem a memória do tempo.

A Cidade é, assim, restituída a sua função primeira: cenário da anamnese de sua comunidade, pois em seus espaços emergem as lembranças e signos das representações culturais de seus habitantes, onde o jogo das origens não tem fim, não se submete à ordem e à classificação dos signos.

\section{Considerações metodológicas em torno da investigação antropológica no mundo} urbano

Em termos conceituais, a polimorfia da vida social no mundo contemporâneo não pode prescindir do estudo das atitudes éticas de seus habitantes nem das qualidades estéticas que envolvem sua expressividade, não podendo ser compreendida, sob pena de reducionismo, a partir de uma démarche do realismo histórico e sociológico deste fenômeno.

Neste sentido, é no plano das motivações simbólicas, das pressões das ambiências sócio-históricas a oferecer constrangimentos às intenções dos atores sociais que se deve

\footnotetext{
${ }^{35}$ Cf. BACHELARD, G. A dialética da duração. São Paulo, Ática, 1988, p. 27.
} 
interpretar a personalidade caótica e confusional da civilização urbana no Brasil e seus espaços de vida coletiva, sob o ponto de vista do que ela expressa como modalidades simbólicas de controle do tempo

Torna-se, assim, fundamental um investigação mais detalhada de novas reflexões metodológicas de pesquisa no meio urbano que levem em conta uma micro-análise da vida social dos grupos humanos que nele habitam, permitindo ao investigador, no exame mais acurado da sua prática etnográfica, atingir as profundezas das atitudes éticas e estéticas que orientam a lógica da desordem da vida citadina local.

Metodologicamente, sugere-se aqui enfocar o acontecimento macroscópico do conjunto civilizacional das cidades brasileiras como totalidade de ordem parcial, engendrada numa multitude de comportamentos coletivos sustentados por uma tradição cotidianamente re-inventada através dos efeitos de agregação de seus grupos urbanos em interação. ${ }^{36}$

No enfoque do mundo urbano contemporâneo, trata-se de atribuir importância à interpretação dos seus fenômenos culturais a partir do estudo da memória coletiva, das lembranças e reminiscências "históricas" dos seus habitantes e do arranjo espacial das formas de vida social apresentadas por eles em seu cotidiano ao longo do tempo.

Considerando a feição macroscópica da configuração desordenada e pluridimensional da geografia urbana do Brasil, torna-se prioritário, portanto, dimensionar o estudo das práticas cotidianas de grupos urbanos como porta de acesso à compreensão da lógica interna que regula a vida citadina do país, deslocando o foco de análise da descrição realista da Cidade na história para um conhecimento compreensivo da Cidade segundo os acontecimentos anódinos que ocorrem no seu interior e a efervescência que rege a vida ordinária de seus habitantes.

Trata-se, então, de se construir parâmetros de interpretação e análise da Cidade nos termos de uma perspectiva do "pensamento da Diferença", conforme apresentado anteriormente. Esta intenção metodológica que aborda o fenômeno urbano a partir de uma "razão hermenêutica" remete ao enfoque da "unidade estilística" da Cidade com seu enfoque como objeto temporal, fora de um círculo vicioso.

Ou seja, a Cidade desponta como fruto da criação perpétua de um querer-viver coletivo plural capaz de estabelecer para si, no cotidiano, uma composição durável no tempo de elementos os mais díspares possíveis (diferenças étnicas, sociais, econômicas, políticas, etc).

\footnotetext{
${ }^{36}$. Cf. SIMMEL, J. Sociologia. Estudios sobre las formas de socializacion. Buenos Aires, Espasa-Calpe, 1984.
} 
Vista em sua heterogeneidade fundamental, da qual é testemunha a vida de seus habitantes, a Cidade ocupa um lugar estratégico para o modelo de interpretação que pressupõe a ambiência urbana no Brasil, tecendo-se a partir da sinergia entre os devaneios do trabalho e do repouso dos grupos humanos que nela habitam. ${ }^{37}$

Para além dos acidentes e circunstâncias diversas que os moradores das grandes cidades brasileiras enfrentam no seu cotidiano, trata-se de enfocar a Cidade e seus territórios como fruto de uma consolidação temporal vivida na errância nas formas de vida social dos grupos urbanos que a ela pertencem, configuradas e re-configuradas em suas narrativas biográficas. $^{38}$

A arquitetura dos vínculos sociais e coletivos na Cidade reveste-se, assim, dos significados que ela tem para os seus diversos atores sociais. É, portanto, no coração da descontinuidade de tempos e espaços sociais sobrepostos que o antropólogo deve situar-se para melhor compreender o acontecimento ambíguo das experiências cotidianas dos habitantes da Cidade, onde se tecem os fenômenos da estética urbana e da memória coletiva.

Este artigo faz, portanto, da teatralidade da vida cotidiana na Cidade um dos aspectos mais significativos de análise e interpretação do fenômeno urbano e uma das dimensões mais significativas de entendimento da vida social de seus moradores. Memória da cotidianeidade e memória coletiva, eis aí dois eixos necessários de participação do antropólogo na formulação da "aura" estética de uma Cidade como fenômeno que se propaga com regularidade e uniformidade face a descontinuidade do vivido de seus habitantes.

Debruçar-se sobre a heteronomia da vida social, mergulhar no arranjo das formas diversas de vida coletiva que configura o fenômeno urbano no Brasil significa para o etnógrafo indagar-se sobre o lugar que este ocupa no diálogo com seus interlocutores, os moradores do local. De um lado, trata-se de investigar o "tempo do mundo" que rege o ritmo dos acontecimentos da vida dos grupos urbanos e, de outro, repertoriar o "tempo imanente" dos sentimentos e emoções coletivas da qual participam tais grupos humanos, inclusive o antropólogo.

Pensando criticamente o realismo etnográfico propagado pela Antropologia em tempos coloniais, este artigo vislumbra a possibilidade de experimentos etnográficos no meio urbano capazes de fornecer a chave de compreensão de uma etnologia do mundo urbano e dos "lugares" de produção dos saberes científicos.

\footnotetext{
37. ANSAY e SCHOONBRODT (Org). Penser la ville, choix de texte philosophique. Bruxelles, AAN Editions, 1989.

${ }^{38}$ Sobre os atos configurante e re-configurante que engendram o tempo na narrativa, cf. RICOEUR, P. Tempo e Narrativa. Volumes I e II. SP, Papirus, 1994.
} 
Com base em experimentos etnográficos em que o antropólogo co-divide, com os moradores das grandes cidades, a descontinuidade lacunar e acidental dos territórios onde a vida urbana se processa, a produção e geração de conceitos e teorias se reconciliam com os gestos e intenções cotidianas e anódinos dos habitantes da Cidade, campo dos conceitos cotidianos de onde emergem os conceitos científicos.

Metodologicamente, opta-se por aproximar o "saber fazer" presente à vida cotidiana dos habitantes das grandes cidades e o "saber por que" que cunha os conceitos científicos da Antropologia. O desafio é transpor conceitos cotidianos e linguagens não-discursivas para o campo de conceitos abstratos com os quais trabalha o antropólogo, tendo por base a idéia central de que um conceito científico não se forma isoladamente, mas numa rede de operações complexas onde conhecimento ordinário se encontra presente como parte de um processo compreensivo do mundo social.

Compreender a ordenação interna das intenções/ações banais humanas no mundo práticas de apropriação do espaço, práticas de deslocamento, de consumo, práticas alimentares, de higiene e de lazer, habitus corporais e gestuais, comportamentos sexuais - a partir de conceitos científicos é descobrir suas invariantes operatórias, possíveis de reconhecimento se houver um mergulho do antropólogo nas trevas do senso comum e de outros discursos e saberes que não acedem a este estatuto. Trata-se, assim, de o antropólogo que pesquisa o mundo urbano contemporâneo perseguir uma observação “pluricontextual”.

Ou seja, "torna-se necessário opor-se aqui ao postulado clássico da pesquisa científica através da qual um mundo 'objetivo' se mostra, independente da descrição (como se uma tal ordem de coisas existisse)" e, neste sentido, todo o conhecimento é auto-poéisis ${ }^{39}$ uma vez que a construção de conceitos sobre o mundo social só é possível de ser feito por alguém que dele participa e que não pode dele se excluir.

O mergulho no ritmo e na intensidade dos gestos, de ações, de dramas e de cenas da vida cotidiana vividos pelos habitantes de grandes centros industriais passa aqui a ser fonte de inspiração e interpretação do antropólogo sobre sua própria situação no mundo que busca compreender, na esteira do vivido humano de seus indivíduos/grupos e de suas estreitas relações com a totalidade territorial da Cidade que os abriga e alimenta.

Os esforços de investigação e produção de novas etnografias para o desvendamento da vida urbana no Brasil, em sua complexidade e constante construção/destruição, exige que o antropólogo cada vez mais aceite o desafio tanto de interpretar a forte carga das motivações

\footnotetext{
${ }^{39}$ Ver a respeito, MATURANA, H. "Reality: the search for objectivity or the quest for a compelling argument. The irish Journal of Psicology, 9 (11), p.53, 1990.
} 
simbólicas dos habitantes de uma Cidade na configuração de seus espaços de convívio coletivo quanto de compreendê-los como espaços humanizados, expressão de suas próprias motivações simbólicas que fazem da Cidade um objeto ímpar para se pensar a "condição humana" no mundo contemporâneo.

Antes de se considerar o mundo urbano contemporâneo como "coisa", volta-se, parafraseando-se Simmel, a uma questão central: “Como é ele possível?". O que é esta consciência que cria a unidade através da ação recíproca de indivíduos e grupos no contato social $?^{40}$ Para responder à tal ordem de problema é que se coloca aqui a necessidade de uma revisão dos conceitos acumulados sobre o fenômeno urbano segundo os esquemas de observação e orientação recíprocos através dos quais se opera esta unidade; é, portanto, conhecê-lo com o outro. Neste contexto, pensar a autoridade dispersa do etnógrafo como tradutor e leitor de contextos específicos onde se inserem as condutas de seus "nativos" remete ao questionamento da análise social do meio urbano a partir de uma visão pluralista da cultura. ${ }^{41}$

Trata-se, pois, de se investir na acuidade da realização de experimentos etnográficos que respeitem as diferenças culturais mantendo-se como fonte de conhecimento antropológico o contraste comparativo das diferenças implícitas entre a retórica autoral do pesquisador e a dos grupos e indivíduos que investiga. ${ }^{42}$

Como receptáculo de um "nós" comunitário, a Cidade no Brasil freqüentemente encontra-se presa a certos postulados de uma épistèmé materialista e seus julgamentos de valores, "coisificada" numa visão patrimonial referida muitas vezes à inscrição secular dos valores e bens materiais de sua comunidade.

De outra forma, receptáculo da "consciência etnográfica", o mundo pós-colonial tem sido, freqüentemente, um convite à quebra da autoridade monológica das etnografias clássicas, de cunho realista, inspirando a criação de novas possibilidades de leituras e escrituras de descrições culturais na tentativa de compreender suas modernas sociedades urbano-industriais e a complexificação de suas regulações.

Com base em processos experienciais, interpretativos, dialógicos e polifônicos através dos quais problematiza-se hoje a prática etnográfica, este artigo insiste na importância de se

\footnotetext{
40 . BOURDARIAS, F. "Norbert Elias: les techniques du regard”. In. Sociétés. Revue des Sciences Humaines et Sociales. Paris, Dunod, n³3, 1991, p. 259.

${ }^{41}$. ROSALDO, R. "Desde la puerta de la tienda de campana: el investigador de campo y el inquisidor". In: CLIFFORD, J. y MARCUS, G. E. (Eds). Retoricas de la Antropologia. Madrid, Serie Antropologia, Jucar Universidad, 1991.

42. MARCUS \& CUSHMAN. in: REYNOSO. 1991. REYNOSO, C. El surgimiento de la antropologia pos moderna. Mexico, Gedisa Editorial, 1991.
} 
re-interpretar a Cidade enquanto unidade estilística ${ }^{43}$ (unidade de "todas as manifestações da vida de um povo"), tendo a memória coletiva e o cotidiano de seus habitantes como elementos da "razão hermenêutica" que tece as articulações internas entre "vida" e "forma" urbana. ${ }^{44} \mathrm{E}$, desta forma, pensar a Cidade, seus territórios e os testemunhos de seus habitantes, como o "conhecimento conjetural" do próprio etnógrafo, conforme os aspectos constitutivos da forma da vida coletiva ao qual pertencem. ${ }^{45}$

No desafio de se construir novos instrumentos narrativos onde a auto-poéisis que representa o processo de construção de conceitos e teorias em Antropologia tenha seu espaço de expressão, reconhece-se que o conhecimento antropológico que se constrói através da descrição etnográfica e da observação participante acena, portanto, para a fragilidade das categorias de interpretação do investigador e a sua própria finitude concebidas aqui como parte de seu continuum de experiências compreensivas do mundo social.

$\mathrm{Na}$ recusa em pensar a prática etnográfica dentro de uma concepção "objetivista" do conhecimento antropológico, este artigo finalmente aponta para a fragilidade do pensamento científico quando ele investe na criação de novas perspectivas metodológicas para a compreensão do trágico social que o conhecimento acerca da Cidade encerra. Trágico social, uma vez que a vida urbana que aí se observa tem um estilo múltiplo e plural, seja na coexistência das conotações assimétricas e ordenadas dos caracteres morfológicos e topológicos de seu dispositivo urbano (bairros, traçados de ruas, edificações, proporções dos prédios, vias de trânsito), seja na co-presença de formas de vida social e de suas figuras diversas através das quais a Cidade compõe-se como ambiência comunitária (laços de vizinhança, errância dos pedestres, nomadismo de grupos urbanos, fluxos lúdicos e profissionais, espetáculos anódinos).

Trágico social, posto que, neste contexto, a crença no trabalho de campo e na observação participante não se efetua como método capaz de garantir, a priori, a autoridade etnográfica do pesquisador tão somente porque ambas as dimensões de investigação recorrem à experiência interpretativa do investigador que põe em jogo a sua própria realidade como pano de fundo de seus juízos científicos.

\footnotetext{
${ }^{43}$. SPLENGER, O. Le déclin de l'Occident. Paris, Gallimard, 1986.

44. CLIFFORD, J. In: REYNOSO. 1991. REYNOSO, C. El surgimiento de la antropologia pos moderna. Mexico, Gedisa Editorial, 1991.

45. VATTIMO, G. Les aventures de la différence, Paris, Editions Minuit, 1985.
} 